\section{Cureus}

\title{
The Effects of Flavonoids on Blood Pressure in Smokers with Hypertension
}

\author{
Enrico Gonsalves ${ }^{1}$, Jeanne-Evelyne Bélanger-Lemay ${ }^{1}$, Nataraj Naidu ${ }^{1}$ \\ 1. St. James School of Medicine, Plaza Juliana 4, Kralendijk, Bonaire, NA \\ $\square$ Corresponding author: Enrico Gonsalves, dctenrico@gmail.com \\ Disclosures can be found in Additional Information at the end of the article
}

\section{Abstract}

A comparison of the relative effect of foods rich in flavonoids (green tea and dark chocolate) on the cardiovascular system of long-term smokers with Stage 1 hypertension has found to reduce systolic blood pressure by $7.4 \mathrm{mmHg}$ and diastolic blood pressure by $6.2 \mathrm{mmHg}$. Long-term smokers $(p=0.05)$ can see their blood pressure reduced by the benefit effect of food rich in flavonoids .

Categories: Cardiology, Internal Medicine

Keywords: smoking, hypertension, blood pressure, flavinoids, chocolate, green tea

\section{Introduction}

Based on the analysis of current literature, we found a statistically significant relationship between the consumption of dark chocolate and a correlating decrease in blood pressure. Chemicals called phytonutrients, or better described as a type of phytonutrient called flavonols, could easily act through complex pathways to mediate this effect [1].

Researchers say the blood pressure-lowering effects of antioxidants appeared to affect the endothelium, the innermost layer of arterial blood vessels that expands and contracts in response to blood flow [2].

"They produced less of the substances that constrict arteries and more of the substances that dilate [expand] the arteries," says researcher Peter Rohdewald, Ph.D, retired professor of pharmaceutical chemistry at the University of Münster in Germany. "That recovery of the function of the endothelium is probably the most beneficial effect for the patients" [3].

Dark chocolate can have a therapeutic effect on hypertension [4]. However, green tea may not have as profound a clinical effect on hypertension as dark chocolate, but it may have a significant effect on cancers [5]. While green tea may not help in chronic hypertension cases, it may help preclude hypertension in the first place. Furthermore, well-statistically-powered studies elucidate that habitual green tea consumption is much more helpful than random green tea consumption in preventing hypertension as well as other co-morbities [6]. Interestingly, some of this healing property may be from caffeine [7]. Thus, many different types of tea may confer similar benefit.

Globally, tea may be the most widely consumed beverage, if water is not considered [8]. The duration of green tea consumption may also play a role in its protective effect [9]. The effect of green tea on blood pressure can be seen in different animal species, even in the background of a mild diabetic-like state [10]. Different types of tea have different profiles for reducing blood 
pressure [7]. Other studies stipulate that hypotensive effects of green tea have been evaluated, with the meta-analysis reporting no effect for green tea and black tea increasing blood pressure, and other trials reporting a decrease in systolic pressure, and decreases in diastolic pressure, and/or no effect [1-2, 11-12].

Dark chocolate may induce a greater decrease in blood pressure than chocolate with less cocoa and flavonoids [4]. With both tea and chocolate, this may have to do with the substances in the products that are actually decreasing the blood pressure.

A meta-analysis conducted by Eric Ding of Harvard Medical School, involved the analysis of 24 chocolate studies involving 1,106 people. It found that dark chocolate, the kind that contains at least 50 to $70 \%$ cocoa, lowered blood pressure in all participants, but most notably in those with hypertension.

Currently, no research has been conducted to investigate the cumulative effect of green tea and dark chocolate. This study's objective is to determine whether the combination of chocolate and green tea can cause a decrease in the blood pressures of chronic hypertensive smokers.

\section{Materials And Methods \\ The null hypothesis $\left(\mathrm{H}_{0}\right)$}

In this study, the null hypothesis $\left(\mathrm{H}_{0}\right)$ states that there is no difference in blood pressure between smokers having a diet rich in flavonoids and smokers who do not have a diet rich in flavonoids.

\section{The alternate hypothesis $\left(\mathrm{H}_{\mathrm{A}}\right)$}

The alternate hypothesis states that there is a change in blood pressure in long-term smokers that have a diet rich in flavonoids.

Participants in the study were compromised of 40 residents of the Island of Bonaire who have been smoking at least one pack of filtered cigarettes per day for six or more years. Research subjects (ideal) were further screened to include those that were hypertensive (BP > 140/90).

\section{Experimental group}

This group constituted of twenty participants. These subjects were required to drink a cup of green tea once a day, along with the additional requirement of eating $10 \mathrm{~g}$ of dark chocolate that contains $86 \%$ of cocoa "Côte d'Or" dark chocolate. This group had blood pressure measurement taken once a week for four weeks. The chocolate and tea required by the participants were provided by the experimenters once a week.

\section{Control group}

This group also had 20 participants, who also had their blood pressure measured once a week for four weeks. No chocolate or green tea was given to this group.

As population variances are unknown but assumed equal, a paired sample T-test was performed to compare the means of the differences in blood pressure. Separate sample T-tests were performed for the changes in diastole and systole blood pressure. The data used for the tests was garnered from taking the differences in systole and diastole blood pressures from week 0 to week four (week 0 data - week four data), week 0 data being the pre-experiment blood pressure 
measurements from the experiment group.

Systole Blood Pressure Analysis:

* Mean for Experiment Group = 7.4 (systole decreases by $7.4 \mathrm{mmHg}$ )

* Mean for Control Group = 0.6 (systole decreases by $-0.5 \mathrm{mmHg}$ )

* Standard Deviation for Experiment Group = 1.95744194

* Standard Deviation for Control Group = 3.647638025

* Pooled Variance $=8.565$

* Degrees of Freedom $=38$

$* \mathrm{p}=0.05$

$* \mathrm{~T}_{\text {critical }}=2.024$

$* \mathrm{~T}_{\text {calculated }}=7.55$

Reject Null as $\mathrm{T}_{\text {calculated }}$ is greater than $\mathrm{T}_{\text {critical }}$

Diastole Blood Pressure Analysis:

* Mean for Experiment Group = 6.2 (diastole decreases by $6.2 \mathrm{mmHg}$ )

* Mean for Control Group = - 0.3 (diastole increased by $0.3 \mathrm{mmHg}$ )

* Standard Deviation for Experiment Group = 5.032525786

* Standard Deviation for Control Group = 4.219004622

*Pooled Variance $=21.5635$

* Degrees of Freedom $=38$

$* \mathrm{p}=0.05$

$* \mathrm{~T}_{\text {critical }}=2.024$

$* \mathrm{~T}_{\text {calculated }}=4.4377$

Reject Null as $\mathrm{T}_{\text {calculated }}$ is greater than $\mathrm{T}_{\text {critical }}$

\section{Results}

\section{Measurements and screening}




\section{Cureus}

\begin{tabular}{|c|c|c|c|c|c|}
\hline Participant & Week 0 Bp & Week 1 Bp & Week 2 Bp & Week 3 BP & Week 4 Bp \\
\hline 1 & $140 / 100$ & 142/102 & 143/102 & $133 / 90$ & $130 / 84$ \\
\hline 2 & $142 / 102$ & $141 / 100$ & 138/90 & $130 / 83$ & $132 / 84$ \\
\hline 3 & $140 / 90$ & $140 / 90$ & 138/88 & 135/84 & $135 / 85$ \\
\hline 4 & $140 / 90$ & $142 / 98$ & $140 / 90$ & 134/98 & $132 / 85$ \\
\hline 5 & $138 / 89$ & $136 / 88$ & 134/86 & 132/84 & 130/82 \\
\hline 6 & $138 / 84$ & $136 / 84$ & $136 / 84$ & 130/80 & $128 / 80$ \\
\hline 7 & 138/90 & $136 / 88$ & $135 / 88$ & 130/88 & $128 / 84$ \\
\hline 8 & $135 / 85$ & $132 / 85$ & 132/82 & 128/82 & $126 / 82$ \\
\hline 9 & 138/88 & $136 / 88$ & 134/88 & 130/80 & 128/78 \\
\hline 10 & $140 / 90$ & $140 / 90$ & 138/98 & 134/98 & 134/85 \\
\hline 11 & 138/78 & $138 / 80$ & 135/82 & $135 / 83$ & $132 / 83$ \\
\hline 12 & $141 / 90$ & $140 / 88$ & 138/88 & $138 / 87$ & $136 / 84$ \\
\hline 13 & 138/88 & 138/90 & 132/86 & $134 / 84$ & $132 / 80$ \\
\hline 14 & $140 / 88$ & $140 / 88$ & 138/84 & $134 / 84$ & $132 / 84$ \\
\hline 15 & $134 / 84$ & $134 / 86$ & $132 / 86$ & $128 / 85$ & 128/82 \\
\hline 16 & 140/92 & 140/92 & 142/92 & 138/78 & $134 / 84$ \\
\hline 17 & 128/86 & $124 / 88$ & $125 / 84$ & 122/82 & 122/82 \\
\hline 18 & $140 / 90$ & $140 / 90$ & $138 / 88$ & $134 / 98$ & $132 / 85$ \\
\hline 19 & $130 / 80$ & $132 / 84$ & $128 / 84$ & $132 / 80$ & $126 / 78$ \\
\hline 20 & $136 / 90$ & $136 / 88$ & 137/88 & $130 / 78$ & $130 / 78$ \\
\hline
\end{tabular}

TABLE 1: Experiment Group Data 


\section{Cureus}

\begin{tabular}{|c|c|c|c|c|c|}
\hline Participant & Week 0 Bp & Week 1 Bp & Week 2 Bp & Week 3 BP & Week 4 Bp \\
\hline 1 & $145 / 88$ & $146 / 86$ & $144 / 90$ & $144 / 90$ & $144 / 92$ \\
\hline 2 & $145 / 100$ & $144 / 88$ & $142 / 88$ & 146/100 & 144/88 \\
\hline 3 & $135 / 88$ & $138 / 90$ & 136/92 & 138/92 & $136 / 94$ \\
\hline 4 & $146 / 88$ & $146 / 84$ & $142 / 88$ & $146 / 90$ & $144 / 90$ \\
\hline 5 & $145 / 94$ & 146/98 & 148/92 & 140/88 & $142 / 86$ \\
\hline 6 & $140 / 86$ & $138 / 84$ & 138/82 & $138 / 80$ & $136 / 84$ \\
\hline 7 & $146 / 84$ & $144 / 88$ & 142/86 & $144 / 84$ & $142 / 86$ \\
\hline 8 & $140 / 86$ & 138/88 & 136/86 & $134 / 88$ & $134 / 90$ \\
\hline 9 & 138/84 & 138/86 & 138/84 & 136/84 & 138/84 \\
\hline 10 & 130/92 & $134 / 88$ & 132/94 & 134/90 & $134 / 90$ \\
\hline 11 & $134 / 86$ & $134 / 88$ & $134 / 88$ & $133 / 90$ & $132 / 90$ \\
\hline 12 & $138 / 90$ & $134 / 88$ & $134 / 92$ & 130/88 & 130/88 \\
\hline 13 & $144 / 86$ & $146 / 92$ & $146 / 94$ & $144 / 92$ & $146 / 90$ \\
\hline 14 & $134 / 90$ & $138 / 94$ & 138/94 & 136/88 & $134 / 90$ \\
\hline 15 & 136/88 & $134 / 90$ & $132 / 88$ & 130/86 & 134/88 \\
\hline 16 & 138/88 & $138 / 90$ & $140 / 88$ & 140/88 & 138/88 \\
\hline 17 & $140 / 88$ & $140 / 86$ & $144 / 88$ & $146 / 90$ & $148 / 90$ \\
\hline 18 & $134 / 90$ & $136 / 92$ & $138 / 88$ & $136 / 90$ & 138/92 \\
\hline 19 & 138/88 & $142 / 86$ & $142 / 86$ & $140 / 86$ & $140 / 88$ \\
\hline 20 & $140 / 96$ & $138 / 94$ & $136 / 98$ & $140 / 96$ & $140 / 98$ \\
\hline
\end{tabular}

TABLE 2: Control Group Data 


\section{Cureus}

\begin{tabular}{|c|c|c|c|c|c|}
\hline & $\begin{array}{l}\text { Changes } \\
\text { Systole }\end{array}$ & $\begin{array}{l}\text { Changes } \\
\text { Diastole }\end{array}$ & & $\begin{array}{l}\text { Changes } \\
\text { Systole }\end{array}$ & $\begin{array}{l}\text { Changes } \\
\text { Diastole }\end{array}$ \\
\hline & 10 & 16 & & 1 & -4 \\
\hline & 10 & 18 & & 1 & 12 \\
\hline & 5 & 5 & & -1 & -6 \\
\hline & 8 & 5 & & 2 & -2 \\
\hline & 8 & 6 & & 3 & 8 \\
\hline & 10 & 4 & & 4 & 2 \\
\hline & 10 & 6 & & 4 & -2 \\
\hline & 9 & 3 & & 6 & -4 \\
\hline & 10 & 2 & & 0 & 0 \\
\hline & 6 & 5 & & -4 & 2 \\
\hline & 6 & -5 & & 2 & -4 \\
\hline & 7 & 6 & & 8 & 2 \\
\hline & 6 & 8 & & -2 & -4 \\
\hline & 8 & 8 & & 0 & 0 \\
\hline & 5 & 2 & & 2 & 0 \\
\hline & 6 & 8 & & 0 & 0 \\
\hline & 6 & 8 & & -8 & -2 \\
\hline & 8 & 5 & & -4 & -2 \\
\hline & 4 & 2 & & -2 & 0 \\
\hline & 6 & 12 & & 0 & -2 \\
\hline Mean & 7.4 & 6.2 & Mean & 0.6 & -0.3 \\
\hline $\begin{array}{l}\text { Standard } \\
\text { Deviation }\end{array}$ & 1.95 & 2.03 & $\begin{array}{l}\text { Standard } \\
\text { Deviation }\end{array}$ & 2.64 & 2.21 \\
\hline
\end{tabular}

TABLE 3: Difference in Systole and Diastole Pressures in Experiment and Control Groups

\section{Discussion}

We can safely reject the null hypothesis that states that there is no difference in blood pressure between smokers having a diet rich in flavonoids and smokers who do not have a diet rich in 
flavonoids. However, we can only reject the null hypothesis with regards to systolic blood pressures as the $\mathrm{p} \backslash_{\text {calculated }}$ value for diastole is less than the $\mathrm{T}_{\text {critical }}$.

Research needs to be conducted to determine the agents and their mechanism of action which result in decreasing hypertension when people eat flavonoids. Current research indicates that the hypotensive effect may be because plasma markers of vasodilating substances increase when people ingest chocolate. Nitric oxide may be the main mediator of such affects. Caffeine mimics adenosine or CAMP. Caffeine will cause hyperpolarization of smooth muscle cells and the flavonoids act on N-oxide cyclic GMP-cytoslic. We would expect them to have a synergistic effect. Caffeine causes most of its "biological effects via antagonizing adenosine receptors which are A1, A2A, A3, and A2B. The mechanism of action could also be more complex because so many things are changed, including blood lipids, blood glucose levels, and insulin sensitivity [13].

A further study is warranted to differentiate between the effects of dark chocolate and green tea. Chocolate may have a larger effect on blood pressure than green tea, but its high calorie content limits its therapeutic use in clinical hypertension often occurring with obesity, compared to green tea [14]. Yet, meta-analysis does show chocolate reduces blood pressure and the clinical implication of this should be further explored.

\section{Experiment concerns}

Attrition was the primary concern for this study, i.e. subjects of the testing group are not necessarily going to consume adequately the amount of dark chocolate and green tea. While it is hard to control the amount of tea or chocolate consumed per day, the accessibility to tea and chocolate was limited to ensure continued participation in the study.

While the experimenters mentioned to the participants in the control group not to consume green tea or dark chocolate, there is no way to be a hundred percent sure that the participants in the control group did not take any dark chocolate or green tea.

Also, it was impossible to discount any bias that may have come from experimenter expectancy as there was no way to disguise the control group from the experiment group. Experimenter expectancy could have occurred if the participants in the experiment group started to exercise or do anything else to reduce their blood pressure. We discounted expectancy by adequately surveying the participants for lifestyle changes.

\section{Conclusions}

N/A

\section{Additional Information \\ Disclosures}

Human subjects: Consent was obtained by all participants in this study. St. James School of Medicine issued approval N/A. Animal subjects: All authors have confirmed that this study did not involve animal subjects or tissue. Conflicts of interest: In compliance with the ICMJE uniform disclosure form, all authors declare the following: Payment/services info: All authors have declared that no financial support was received from any organization for the submitted work. Financial relationships: All authors have declared that they have no financial relationships at present or within the previous three years with any organizations that might have an interest in the submitted work. Other relationships: All authors have declared that there are no other relationships or activities that could appear to have influenced the submitted 


\section{Cureus}

work.

\section{References}

1. Brown AL, Lane J, Coverly J, et al.: Effects of dietary supplementation with the green tea polyphenol epigallocatechin-3-gallate on insulin resistance and associated metabolic risk factors: Randomized controlled trial. Br J Nutr. 2009, 101:886-894.

2. Fukino Y, Ikeda A, Maruyama K, Aoki N, Okubo T, Iso H: Randomized controlled trial for an effect of green tea-extract powder supplementation on glucose abnormalities. Eur J Clin Nutr. 2008, 62:953-960.

3. (2005). http://www.webmd.com/hypertension-high-bloodpressure/news/20040220/antioxidant-help-lower-blood-pressure.

4. Nordmoe, E. D: Kiss high blood pressure goodbye: The relationship between dark chocolate and hypertension. Teaching Statistics. 2008, 30:34-38.

5. Clement Y: Can green tea do that? A literature review of the clinical evidence . Preventive Medicine . 2009, 49:83-87.

6. Green tea consumption prevents hypertension. Cortlandt Forum. 2004, 17:25.

7. Sowa C, Halevy J: Letters from our readers . Better Nutrition. 2004, 66:8.

8. Cheng TO: All teas are not created equal: The Chinese green tea and cardiovascular health . Int J Cardiol. 2006, 108:301-308.

9. Boylan M: Green and oolong tea reduces risk of developing hypertension . Journal Of The Australian Traditional-Medicine Society. 2005, 11:77.

10. Sun Hwang L, Liang-Yi W, Chi-Chang J, Yung-Pei H, Pei-Hsuan Ho L, Low-Tone H: Green tea supplementation ameliorates insulin resistance and increases glucose transporter IV content in a fructose-fed rat model. European Journal Of Nutrition. 2004, 43:116-124.

11. Hooper L, Kroon PA, Rimm EB, et al.: Flavonoids, flavonoid-rich foods, and cardiovascular risk: A meta-analysis of randomized controlled trials. Am J Clin Nutr. 2008, 88:38-50.

12. Matsuyama T, Tanaka Y, Kamimaki I, Nagao T, Tokimitsu I: Catechin safely improved higher levels of fatness, blood pressure, and cholesterol in children. Obesity (Silver Spring). 2008, 16:1338-1348.

13. Dark Chocolate May Help Hypertension. Tufts University Health \& Nutrition Letter. 2005, 23:1-2.

14. Ried K, Frank O, Stocks N: Chocolate and Blood Pressure. BMJ: British Medical Journal (Overseas \& Retired Doctors Edition). 2010, 341:318. 